\title{
VALUE OF TIME FOR COMMERCIAL VEHICLE OPERATORS
}

Value of time was estimated for commercial vehicle operators in Minnesota to quantify the effects of spring load restrictions. A sample was constructed from several trucking industry sources to conduct a survey. Interviews were conducted using an adaptive stated preference (ASP) survey to derive an estimate to the nearest dollar.

A tobit model was fit to the data from the interviews to derive the estimate for value of time, $\$ 49.42$ per hour. Variation in the distribution of values is explained in part by fleet operation: whether the firm operates as a for-hire carrier or a private carrier.

\section{by Brian Smalkoski and David Levinson}

The spring load restriction (SLR) policy, also known as seasonal load restrictions, was enacted in Minnesota in 1937 (Minnesota Statute 169.87) to protect the large public investment in roadway facilities. In cold regions, pavement strength varies with seasonal change. The spring thaw introduces a saturated condition in the soil under the pavement. Under this condition the load-bearing capacity of the roadway is reduced and heavy trucks driving on this roadway can cause additional damage.

The SLR policy seeks to reduce this damage and extend the life of pavements by restricting the weight of commercial vehicles during the spring season. The restrictions impose costs on commercial vehicle operators while benefiting society by extending pavement life. This research is part of a larger study that aims to quantify these costs and benefits.

The cost of SLR on commercial vehicle operators is assumed to be the consequence of alternate behavior resulting from the imposition of the restrictions. This alternate behavior can be summarized as any of the following options: shift the seasonal timing of shipments, reduce load size per vehicle (resulting in more trips), change vehicle type, or change routes (to longer but less restricted roadways). All these behaviors add costs to the operation of commercial vehicles.

A cost per kilometer or value of time is needed to determine the actual cost to industry as a result of the policy. To obtain a meaningful estimate of the value of time for commercial vehicle operators in Minnesota new research needed to be undertaken. The body of this paper illustrates how this analysis was done, outlines the theory supporting it, and provides an estimate to be used in the cost-benefit analysis of the SLR policy.

This paper is organized in five sections. The second section provides an overview of the theory that was used as a building block for the analysis. It details the methodology used in the interview and surveying process. The third section presents the results of the interviews. The fourth section explains the variation in results. Finally, the conclusion summarizes the findings and their relation to the cost-benefit study and discusses further analysis.

\section{THEORY AND METHODOLOGY}

The value of time for vehicles has been evaluated for more than 40 years, since it was noted to be an important part of economic analysis in transport planning (Bruzelius 1979). Haning and McFarland (1963) published one of the first reports estimating the value of time for commercial vehicles. They evaluated time savings through the "net operating profit" approach. This approach makes the assumption that business-oriented travel time saved is used for productive purposes, whereas personal travel time saved may be used for productive purposes or leisure activity. Thus commercial vehicle value of time should be greater even when no cargo is being carried. Their methodology fixed most vehicle and labor costs so that with improved 
speeds, a vehicle will be able to travel farther in the same time and contribute more profit. The difference between the base condition and the improved speed condition was the value of time savings.

Adkins, Ward, and McFarland (1967) used a "cost savings model" to estimate the value of time for commercial vehicles, which is "based on a reduction of those costs that are not variable with miles of operation." They also reviewed two additional methods of estimation: the "cost-of-time" method in which the value of time is "derived by determining the cost of providing time savings" for a specific project, and the "willingness-to-pay" method in which "individuals are faced with a decision between time savings and other benefits." A summary of some previous results is provided in Table 1, adapted from Kawamura (1999). The Consumer Price Index (2003) was used to adjust the figures to reflect 2003 prices.

Over the past decade, several European papers have used willingness-to-pay methods (Bergkvist 2000, Nerhagen 2001, Wynter 1995). They used both revealed and stated preference methods to derive choice data. Revealed preference (RP) refers to preferences observed in actual market situations. Stated preference (SP) refers to preferences recorded in hypothetical situations. While economists typically are reluctant to rely on stated consumer preference compared with observing actual consumer behavior, in many situations the choice for researchers is to take consumers at their word or do nothing (Louviere, Hensher, and Swait 2000).

SP methods have several advantages over RP methods. Louviere, et al. (2000) state how SP surveys can be designed to control for outside influences whereas data from RP methods sometimes cannot satisfy model assumptions, thus observed relationships cannot provide reliable and valid inferences. SP data are often less expensive to collect. SP methods are used widely in marketing studies to explain preference for items that are not in the actual marketplace. SP can introduce variability in explanatory variables to estimate preference where little variation exists in the marketplace.

In the case of this cost-benefit analysis of SLR, there is very little available market-choice data in instances where proper demand equations could be derived to estimate a value of time. One is limited to the use of SP methods, from which one can apply econometric models to estimate the value of time from the stated choices of commercial truckers.

\section{The Commercial Vehicle Operator Sample}

A sample of commercial vehicle operators is necessary to conduct an analysis of their value of time. The sample of the population for this analysis was constructed from many sources: Minnesota Department of Transportation (Mn/ DOT) Freight Facilities Database, Mn/DOT filed insurance list, $\mathrm{Mn} / \mathrm{DOT}$ overweight permit list, Minnesota Trucking Association (MTA) board of directors, and firms identified by an independent survey of city and county engineers throughout the state.

A survey was initially constructed and mailed to the sample to gather general information on the companies, the effects of SLR on their operations, and their willingness to participate in an interview. They were mailed during the spring of 2003. An interview was chosen for the SP component rather than telephone or mailed methods because the interviewer can be available for clarifying and follow-up questions,

Table 1: Summary of Previous Value of Time Studies

\begin{tabular}{|c|c|c|c|c|c|}
\hline Authors & Year of Publication & Focus & Location & Adjusted to 2003 & Average Value Per Hour \\
\hline Haning and McFarland & 1963 & Truck Operators & & $\$ 19.57$ to $\$ 25.42$ & $\$ 22.50$ \\
\hline Waters et al. & 1995 & Truck Operators & & $\$ 6.86$ to $\$ 38.92$ & $\$ 22.89$ \\
\hline Kawamura & 1999 & Truck Operators & & $\$ 30.14$ & $\$ 30.14$ \\
\hline Brownstone et al. & 2003 & Autombiles & San Diego, CA & $\$ 30.58$ & $\$ 30.58$ \\
\hline Lam and Small & 2001 & Autombiles & California & $\$ 21.36$ & $\$ 21.36$ \\
\hline Adkins et al. & 1967 & Cargo Vehicles & & $\$ 25.81$ & $\$ 25.81$ \\
\hline & & & & $\begin{array}{c}\text { Overall Average } \\
\text { Standard Deviation }\end{array}$ & $\begin{array}{l}\$ 25.55 \\
\$ 4.01\end{array}$ \\
\hline
\end{tabular}


Commercial Vehicle Operators

allowing the subject to gain a clearer grasp of the scenarios presented and their trade-offs (Kawamura 1999).

Of the 441 actual responses from the mailed survey, $50.9 \%$ were willing to be interviewed. For the cost-benefit analysis of SLR, four Minnesota counties were modeled: Olmsted, Lyon, St. Louis, and Clay. The counties were chosen based on available data and geographic location. These four counties are located in different parts of the state and represent a different mix of commodity flows representative of their respective locations. To remain consistent, the interviews were to be conducted in these same counties. Only 40 candidates were willing to be interviewed from these four counties, so the sample area was increased to include neighboring counties. A pilot study was conducted in Hennepin County because of its close proximity to the University of Minnesota and to include some metropolitan data. In all, 50 interviews were conducted throughout 12 counties during July and August of 2003 (Figure 1).

\section{The SP Experiment}

Several options are available in designing an SP survey. Preferences can be reported as rankings, choices between two or more options, or as ratings of each individual option. Stated choice was chosen for this experiment because ranking and

Figure 1: Interview Locations for SP Analysis

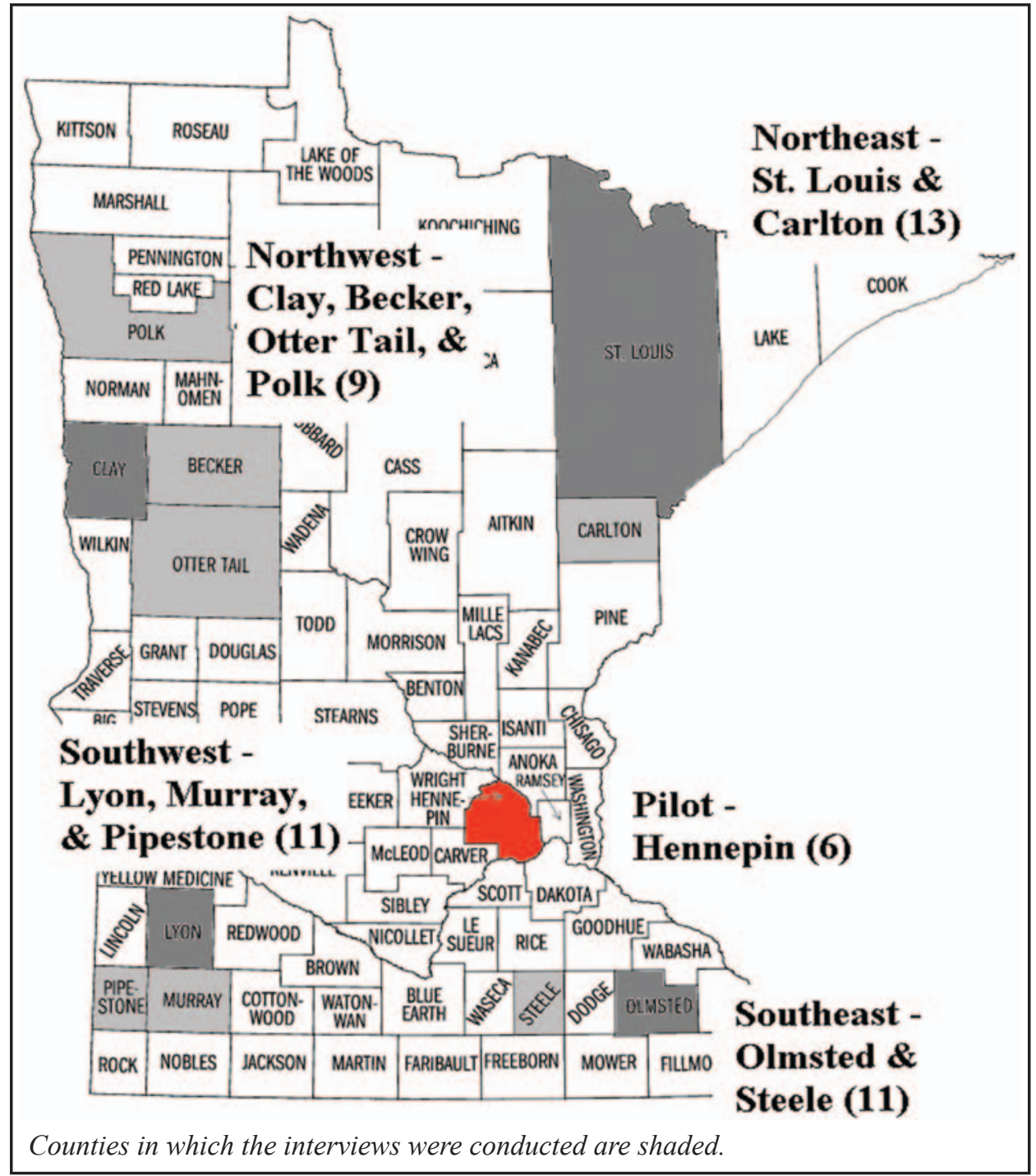


rating of alternatives seems to be an unusual activity in transportation (Kawamura 1999). Also, discrete choice data has been shown to be less sensitive to bias when compared with other methods such as rating and ranking (Wynter 1995). The options are described by attributes set to particular levels. "It is usual, because it provides useful data, to choose attribute levels such that alternatives do not dominate each other, i.e. are not better in all respects. Instead, trade-offs are built into the experiment, where respondents are given more of one good (or less of a bad) in return for less of another good (or more of a bad)" (Fowkes 2001).

The chosen design for the analysis employed adaptive stated preference (ASP) methodology. ASP surveys differ from conventional SP surveys in four major ways: (1) options presented in subsequent games depend on the answers recorded in previous games, (2) fewer alternatives and attributes are presented in individual games, (3) the subject is often presented with more games, and (4) it is possible to obtain estimates of parameters at the individual level (Richardson 2002). The last reason is the most important reason this methodology was chosen, since value of time is estimated at the disaggregate level.

The design of the commercial vehicle survey included the often-utilized permit schemes of Mn/DOT and several municipalities as an attribute, in addition to time per truckload, total truckloads, and the expected value of the fine. The permit would allow the truck to travel on an otherwise restricted route to save travel time for a fee. Two options of permits were presented, a seasonal permit that would allow a truck to travel overweight for the entire duration of SLR, or a single-use permit that would allow the truck to exceed the restriction for one trip. The expected value of a fine is the product of the fine and the probability of getting caught. Fines for overweight trucks are on the order of hundreds of dollars, but the probability of getting caught is less than $10 \%$. The expected value of fine is the product of full fine value and the probability of getting caught, one figure for simplicity.

The adaptive technique presented one nocost option and one cost option in exchange for time or truckload savings. There were five scenarios (each with six games): trading a reduction in time per truckload for a single-use permit, trading a reduction in total truckloads for a single-use permit, trading a reduction in total truckloads for a seasonal permit, trading a reduction in time per truckload for an expected value of fine, and trading a reduction in total truckloads for an expected value of fine.

The interviews were conducted and the survey was administered on a laptop computer. A computer program running through a Microsoft Access database was used to alter values in the separate presentations. The computer program used bisection techniques to focus on each subject's maximum willingness to pay. It started at a midpoint of an appropriate range and increased or decreased the cost attribute by half depending on the alternative chosen by the subject. This process continued until a reasonable amount of precision was reached; in this case values to the nearest $\$ 1$ or $\$ 2$. A reasonable starting point should be two to three times the final mean (Richardson 2002). The average values in previous studies indicated that the starting point should be around $\$ 50$ per hour. Instead, \$40 was chosen for its meaningful integer values when bisected up to the fourth iteration. This makes the range of possible values of time from $\$ 1.25$ up to $\$ 77.75$ for the six iterations. The full range is $\$ 0$ to $\$ 80$, but these values represent the limits to which infinite iterations would be bound.

A screenshot of the database displays the instructions and layout of presentation two, the first tradeoff scenario (Figure 2). The question would repeat a total of six times with a different value for option $\mathrm{B}$ after each response. The subsequent values depend on the previous choice for each scenario with the program resetting at $\$ 40$ for each of the other scenarios. The complete list of questions is given in the appendix.

The range was tested for validity in the pilot study, along with the language of the instructions, SP and interview questions, as well as SP format and database functionality. ${ }^{1}$ The average value given was $\$ 19.74$ per hour, the minimum was $\$ 0$, the maximum was $\$ 45$ per hour, and the average of the maximums was $\$ 33.33$ per hour. These values confirmed that the chosen anchor and maximum points were sufficient, and all bugs in the operation of the database and all misinterpretations of 


\section{Figure 2: Scenario 1 - A Tradeoff of a Reduction in Time per Truckload for a} Single Use Permit

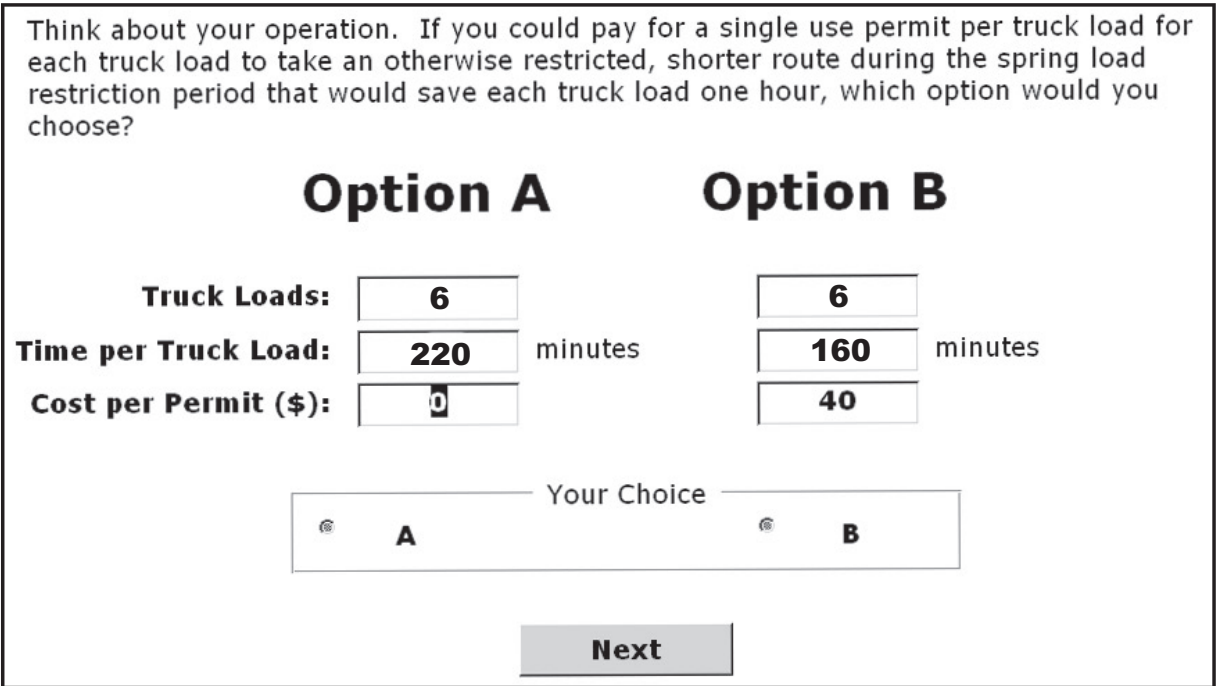

instructions were eliminated prior to travel to the four study areas.

Extraction of value-of-time estimates from SP data can be obtained with two different methods, switching point analysis and statistical analysis. Switching point analysis estimates the value of time from the level of trade-off where the choices switch from the cost option to the free option (Kawamura 2000). An example would be a traveler who chooses to pay a toll for a given amount of time savings on all options up to $\$ 5$, but then chooses the alternate route without a toll for all tolls over $\$ 5$. The switching point for this individual is $\$ 5$, and would be an estimate of that traveler's value of time.

The logit model has been widely used to estimate the value of time from discrete choice data. It assumes that the error terms are Gumbel distributed. Using the logit model for aggregate estimation yields utility coefficients that reflect average behavior. If the objective of the analysis is to measure differences in coefficient values across individuals, aggregate estimation is contradictory (Kawamura1999). Various suggestions have been presented to handle this problem including introducing socioeconomic variables, relaxing assumptions, or segmenting the data. Fowkes (2001) suggests fitting individual models for each respondent. Further analysis can be conducted by aggregating the fitted disaggregate models.
In cases of truncated data, data that has lower and/or upper limiting values, there may be a number of responses that take on the limiting value. In this situation, logit analysis would be inappropriate. Probit analysis would provide a suitable model of the probability of responses taking on the limiting value, and regression analysis would be appropriate for the non-limited values. Tobin (1958) proposed a model that is a hybrid of these two techniques for cases of truncated data.

\section{RESULTS}

The first presentation measured the preference for saving truckloads for a particular shipment versus time per truckload for that same shipment. The mean final value of truckloads and time per truckload were near the midpoint of the analysis, thus no clear indication of preference for time savings or truckload savings was indicated. For the value-of-time analysis, the estimates from the two scenarios of truckload savings and time per truckload savings will be based on the product of the two, the total time savings.

The results of the switching point analysis yielded an overall mean value of time of $\$ 24.10$ per hour (Table 2). The values presented are descriptive statistics based on the greatest value of the non-free alternative that the respondent chose in the ASP survey. 
The second presentation, time savings in exchange for a single-use permit, has the greatest switching point mean of $\$ 36.70$ per hour. The lowest mean value of time corresponds to the seasonal permit scenario (P4), followed closely by the fine scenarios. The mean value of time of all the presentations for all 50 survey participants is $\$ 24.10$ per hour. This is in line with the past studies' estimates of the value of time (Table 1).

Typically in value-of-time analysis, the mean of the switching points is referred to as the estimate of the value of time. Most SP surveys have a similar structure as was used in presentation two where time is saved as a result of paying a fee, in most cases a toll, but in this case, a single use permit. Brownstone et al. (2003) have noted that SP studies generally yield lower values than RP studies. Avoidance of paying additional fees for a public good that people believe they had already paid for in the form of taxes may explain this underestimate. Some respondents noted that they would not purchase permits, but were more willing to pay fines to save time. Using only permits to estimate value of time would not capture this group of respondents' actual willingness to pay. The maximum switching points for each respondent would take into account those who are unwilling to pay additional fees, but still have a willingness to pay using other means (e.g. fines) in other scenarios. Similarly it would account for those who would not be willing to break the law and receive fines, but would pay extra for permits. The mean of those maximum switching points is $\$ 46.78$ per hour (Table 2). The use of this value is likely to represent a varied sample's maximum willingness to pay and therefore more accurately estimate the value-of-time.

One problem that was encountered in this analysis is that some cases were bounded by the survey instrument's computer program that adaptively adjusted the values of the fines and

Table 2: Switching Point Analysis

\begin{tabular}{|c|c|c|c|c|c|c|c|c|c|c|}
\hline & \multicolumn{3}{|c|}{ P1: } & \multirow[b]{2}{*}{$\begin{array}{l}\text { P3: } \\
(\$)\end{array}$} & \multirow[b]{2}{*}{$\begin{array}{l}\text { P4: } \\
(\$)\end{array}$} & \multirow[b]{2}{*}{$\begin{array}{c}\mathrm{P} 4 / 40: \\
(\$)\end{array}$} & \multirow[b]{2}{*}{$\begin{array}{l}\text { P5: } \\
(\$)\end{array}$} & \multirow[b]{2}{*}{$\begin{array}{l}\text { P6: } \\
(\$)\end{array}$} & \multirow[b]{2}{*}{$\begin{array}{c}\text { Mean } \\
(\$)\end{array}$} & \multirow[b]{2}{*}{$\begin{array}{c}\operatorname{Max} P \\
(\$)\end{array}$} \\
\hline & $\begin{array}{c}\text { P1: } \\
\text { Trucks }\end{array}$ & $\begin{array}{l}\text { Time } \\
\text { (min.) }\end{array}$ & $\begin{array}{l}\text { P2: } \\
(\$)\end{array}$ & & & & & & & \\
\hline Mean & 5.82 & 176.61 & 36.70 & 30.23 & 653.41 & 16.34 & 19.50 & 17.35 & 24.10 & 46.78 \\
\hline Median & 5.00 & 176.00 & 38.75 & 13.75 & 300.00 & 7.50 & 3.75 & 1.88 & 10.00 & 48.75 \\
\hline Mode & 4.00 & 120.00 & 0.00 & 0.00 & 0.00 & 0.00 & 0.00 & 0.00 & & \\
\hline Max & 8.00 & 240.00 & 78.75 & 78.75 & $3,150.00$ & 78.75 & 78.75 & 78.75 & & \\
\hline Min & 4.00 & 120.00 & 0.00 & 0.00 & 0.00 & 0.00 & 0.00 & 0.00 & & \\
\hline Standard & & & & & & & & & & \\
\hline Deviation & 1.85 & 55.44 & 28.10 & 30.34 & 857.82 & 21.45 & 27.86 & 25.88 & 27.98 & 27.07 \\
\hline
\end{tabular}

Notes:

- $P$ refers to presentation.

- P1 is a scenario where there is a trade-off between truckloads versus time per truckload.

- P2 is a scenario where there is a trade-off between hour of time savings for each truck with a single-use permit versus no time savings for zero cost.

- P3 is a scenario whre there is a trade-off between a savings of one truckload with a single-use permit versus no truckload savings for zero cost.

- P4 is a scenario where there is a trade-off of having to run fewer truckloads over the SLR period for the cost of a seasonal permit, or more truckloads for the same amount of product for zero cost.

- P4/40 adjusts the 40 hours of time savings to one hour.

- P5 is similar to the second presentation, except in this case fines are used instead of single-use permits.

- P6 is the same as P3, except that fines were used in the place of single-use permits. The second set of data presented in this table averages the two single-use permit scenarios and the two fine scenarios. 
permits based on previous answers. The program was bounded at $\$ 0$ so that no one would receive payment for time savings. The expectation was that no individual value of time would exceed $\$ 78.75$ per hour throughout the experiment as corroborated by the pilot study. However, eight subjects reached the maximum willingness to pay during at least one presentation. Two options are available when working with bounded data: either throw out the bounded cases due to the fact that they violate the homogeneity assumption for the data, or use all the data with a model that accounts for limited cases. A tobit model accounts for limited cases; this model will be fit to the data in a later section.

The estimate for value-of-time with the bounded cases eliminated reduced the previous estimate of maximum switching points by $\$ 4.06$ to $\$ 42.72$ per hour (Table 3). In Table 3, the two lower-bounded cases and the eight upper-bounded cases were eliminated, leaving 40 firms for the analysis.

The results for the logit model when analyzed at the extreme disaggregate level of each presentation for each subject are equivalent to the switching point analysis.

(1) Utility $=\beta_{0}+\beta_{1}(\Delta$ Cost $)+\beta_{2}(\Delta$ Time $)$

If the data are aggregated to the individual level, the results of the logit analysis are roughly equivalent to the mean of presentations for the switching point analysis as shown in Table 4 . One difference is that the mean increases by eliminating the bounded cases, whereas the mean decreases in the switching-point analysis. These results should not be given much consideration because only three out of 40 individuals had significant coefficients for time and cost at the $95 \%$ confidence interval. This is consistent with previous research (Lam and Small 2001, and Louviere et al. 2000). Aggregating the data at the presentation level results in large differences in value-of-time estimates (Table 5). Thus, logit analysis must be done at the disaggregate level, and in this case the results are equivalent to those presented in the switching-point analysis section.

The main problem with the previous analysis is the limited cases. The tobit model can be fitted to truncated data without eliminating cases. It provides additional information, and thus will provide a better estimate of the value of time. The tobit model used in this analysis uses the maximum switching point as the dependent variable with a constant as the independent variable and an upper limit of $\$ 78.75$ per hour. The estimate for the independent variable parameter is $\$ 49.42$ per hour using all 50 cases. The estimate is statistically significant with a $t$-statistic of 11.07 .

The best result from these data to be used as an estimate of the commercial vehicle operator's value of time is $\$ 49.42$ per hour. It accounts for people's aversion to paying for something that they feel they have already paid for by including fine scenarios and choosing the maximum from all presentations. It also uses all data collected in the derivation of the estimate.

A check for this estimate of value-of-time would be to take the stated cost per kilometer reported by the subjects and multiply that by a reasonable estimate of kilometers per hour $(\mathrm{km} / \mathrm{h})$. The average stated cost for the subjects is $\$ 0.65$ per $\mathrm{km}$. From the interviews, $80 \mathrm{~km} / \mathrm{h}$ was considered a reasonable expectation for the speed of trucks. The result is $\$ 52$ per hour, which is in line with the estimate from the tobit analysis.

\section{VARIATION BY TYPE OF CARRIER AND FACILITY TYPE}

One aim of this study was not only to provide an accurate estimate for commercial vehicle operator's value of time in Minnesota, but also to account for the variation in value of time. The recorded values of time comprise a very flat distribution with variance exceeding the mean exponentially. The mailed survey recorded many operational and economic details of each firm so that they could be used in further analysis as independent variables to test for a statistically significant relationship.

Kawamura (2000) showed that the value of time varies at a significant level based on the operation of the trucking firm, whether it is a private or for-hire carrier. This hypothesis was tested using the tobit model. The indicator variable for private carriers was significant at 
Commercial Vehicle Operators

\section{Table 3: Switching Point Analysis - Bounded Cases Eliminated}

\begin{tabular}{|c|c|c|c|c|c|c|c|c|c|c|}
\hline & & P1: & & & & & & & & \\
\hline & $\begin{array}{c}\text { P1: } \\
\text { Trucks }\end{array}$ & $\begin{array}{l}\text { Time } \\
\text { (min.) }\end{array}$ & $\begin{array}{l}\text { P2: } \\
(\$)\end{array}$ & $\begin{array}{l}\text { P3: } \\
(\$)\end{array}$ & $\begin{array}{l}\text { P4: } \\
(\$)\end{array}$ & $\begin{array}{c}\mathrm{P} 4 / 40: \\
(\$)\end{array}$ & $\begin{array}{l}\text { P5: } \\
(\$)\end{array}$ & $\begin{array}{l}\text { P6: } \\
(\$)\end{array}$ & $\begin{array}{c}\text { Mean } \\
(\$)\end{array}$ & $\begin{array}{c}\operatorname{Max} P \\
(\$)\end{array}$ \\
\hline Mean & 5.50 & 184.09 & $\$ 34.81$ & $\$ 26.44$ & $\$ 605.88$ & $\$ 15.15$ & $\$ 15.44$ & $\$ 13.56$ & $\$ 21.22$ & $\$ 42.72$ \\
\hline Median & 4.50 & 192.00 & $\$ 36.25$ & $\$ 10.63$ & $\$ 325.00$ & $\$ 8.13$ & $\$ 2.50$ & $\$ 1.88$ & $\$ 10.00$ & $\$ 48.75$ \\
\hline Mode & 4.00 & 240.00 & $\$ 5.00$ & $\$ 0.00$ & $\$ 0.00$ & $\$ 0.00$ & $\$ 0.00$ & $\$ 0.00$ & & \\
\hline Max & 8.00 & 240.00 & $\$ 77.50$ & $\$ 77.50$ & $\$ 2,800.00$ & $\$ 70.00$ & $\$ 70.00$ & $\$ 70.00$ & & \\
\hline Min & 4.00 & 120.00 & $\$ 0.00$ & $\$ 0.00$ & $\$ 0.00$ & $\$ 0.00$ & $\$ 0.00$ & $\$ 0.00$ & & \\
\hline Standard Deviation & 1.76 & 54.93 & $\$ 25.85$ & $\$ 26.89$ & $\$ 792.75$ & $\$ 19.82$ & $\$ 23.31$ & $\$ 20.00$ & $\$ 24.67$ & $\$ 24.12$ \\
\hline
\end{tabular}

Notes:

- $P$ refers to presentation.

- P1 is a scenario where there is a trade-off between truckloads versus time per truckload.

- P2 is a scenario where there is a trade-off between hour of time savings for each truck with a single-use permit versus no time savings for zero cost.

- P3 is a scenario where there is a trade-off between a savings of one truckload with a single-use permit versus no truckload savings for zero cost.

- P4 is a scenario where there is a trade-off of having to run fewer truckloads over the SLR period for the cost of a seasonal permit, or more truckloads for the same amount of product for zero cost.

- P4/40 adjusts the 40 hours of time savings to one hour.

- P5 is similar to the second presentation, except in this case fines are used instead of single-use permits.

- P6 is the same as P3, except that fines were used in the place of single-use permits. The second set of data presented in this table averages the two single-use permit scenarios and the two fine scenarios.

Table 4: Logit Results - Individual Firms

\begin{tabular}{ccc}
\hline & All Cases $(\$ /$ hour) & Bounded Cases Eliminated (\$/hour) \\
\cline { 2 - 3 } Mean & 24.92 & 26.58 \\
Median & 14.70 & 14.80 \\
Mode & & \\
Max & 85.33 & 85.33 \\
Min & 0.46 & 1.89 \\
Standard Deviation & 23.60 & 24.19 \\
\hline \hline
\end{tabular}


Commercial Vehicle Operators

Table 5: Logit Results, by Presentation - Bounded Cases Eliminated

\begin{tabular}{|c|c|c|c|c|c|}
\hline Presentation & $\Delta \mathrm{T}$ & $\Delta \mathrm{C}$ & $\Delta \mathrm{T} / \Delta \mathrm{C}$ & VOT (\$/hour) & Significant \\
\hline 2 & 1 & 0.0106 & 93.9 & 93.92 & \multirow{5}{*}{$* *$} \\
\hline 3 & 1 & 0.0116 & 86.3 & 86.34 & \\
\hline 4 & 1 & -0.0002 & -115.7 & 115.74 & \\
\hline 5 & 1 & 0.0177 & 56.5 & 56.48 & \\
\hline 6 & 1 & 0.0148 & 67.7 & 67.69 & \\
\hline \multicolumn{4}{|c|}{ Mean } & \multicolumn{2}{|c|}{84.04} \\
\hline \multicolumn{4}{|c|}{ Median } & \multicolumn{2}{|c|}{86.34} \\
\hline \multicolumn{6}{|c|}{ Mode } \\
\hline \multicolumn{4}{|c|}{ Max } & \multicolumn{2}{|c|}{115.74} \\
\hline \multicolumn{4}{|c|}{ Min } & \multicolumn{2}{|c|}{56.48} \\
\hline \multicolumn{4}{|c|}{ Standard Deviation } & \multicolumn{2}{|c|}{23.10} \\
\hline $\begin{array}{l}\text { Notes: } \\
\text { - } \quad \Delta T \text { reflects } \\
\text { - } \quad \Delta C \text { reflect } \\
\text { - } \quad \Delta T / \Delta C \text { ref } \\
\text { - } \quad \text { VOT is the } \\
\text { - } \quad * * \text { denotes }\end{array}$ & $\begin{array}{l}\text { char } \\
\text { chat } \\
\text { the } \\
\text { olute } \\
\text { nifice }\end{array}$ & $\begin{array}{l}\text { n time. } \\
\text { n cost. } \\
\text { tion of ti } \\
\text { ue of } \Delta T / 2 \\
\text { at } 5 \% \text { le }\end{array}$ & avings. & & \\
\hline
\end{tabular}

the $90 \%$ level. The results are consistent with Kawamura's findings that private carriers have a considerably lower value-of-time (Table 6). This can be explained by for-hire firms having a better idea of their operating costs and the greater flexibility to pass most of the additional cost on to the consumer.

The freight facility database has records organized by facility type (Table 7 ). The hypothesis that for-hire carriers have a higher value of time is tested and the results are consistent with previous results. The for-hire carriers have the greatest value of time $(\$ 78.09-\$ 19.79=\$ 58.30$ per hour); all other facility types included in the analysis have private fleets, and as indicated by the data in Table 7, they all have a lower value of time. Three facility types are significant at the $90 \%$ level, with two more being almost significant.
Most variables, especially continuous variables such as those indicating firm size (number of trucks, employees, etc.), failed to account for the variation in value of time estimates across individuals. This is consistent with the literature; only Kawamura's (2000) study has postulated and provided evidence for an explanatory variable or variables.

\section{CONCLUSION}

This paper used six scenarios of Adaptive Stated Preference (ASP) to estimate the value of time for commercial vehicle operators in Minnesota. The games within each scenario were bounded by 'reasonable' estimates of the value of time, and during the course of the analysis several subjects reached the upper limit of the survey. The best model for truncated data of this type is the tobit

Table 6: Tobit Model, Private vs. For-Hire Carriers

\begin{tabular}{ccccccc}
\hline & Estimate & Standard Error & t-statistic & P-value & 95\% Confidence Interval \\
\cline { 2 - 7 } Constant & 59.5962 & 6.715904 & 8.87 & 0 & 46.10009 & 73.09232 \\
Private & -17.23666 & 8.641082 & -1.99 & 0.052 & -34.60156 & 0.1282455 \\
\hline \hline
\end{tabular}




\section{Table 7: Tobit Model, by Freight Facility Type}

\begin{tabular}{ccccccc}
\hline & & & & & & \\
& & & & & & \\
Estimate & Standard Error & t-statistic & P-value & 95\% Confidence Interval \\
\cline { 2 - 6 } Constant & 78.09 & 16.04 & 4.87 & 0 & 45.77 & 110.42 \\
Ag Chem & -56.43 & 21.98 & -2.57 & $0.014^{*} *$ & -100.72 & -12.13 \\
Grain & -34.80 & 20.03 & -1.74 & $0.089 *$ & -75.18 & 5.57 \\
Manufacturing & -34.34 & 20.65 & -1.66 & 0.103 & -75.97 & 7.28 \\
For-Hire Trucking & -19.79 & 16.82 & -1.18 & 0.246 & -53.68 & 14.11 \\
Waste & -50.59 & 30.57 & -1.65 & 0.105 & -112.21 & 11.02 \\
Wholesale & -54.52 & 18.81 & -2.9 & $0.006 * *$ & -92.44 & -16.60 \\
\hline
\end{tabular}

Notes:

- Ag Chem refers to Agriculture Chemical Distribution Centers.

- *denotes significance at $10 \%$ level.

- **denotes significance at 5\% level.

-***denotes significance at $1 \%$ level.

model. The tobit model provided an estimate for the average commercial vehicle value of time in Minnesota of $\$ 49.42$ per hour. This result is very similar to the median of the maximum of presentations of $\$ 48.75$ per hour using switching point analysis with bounded cases eliminated. Comparisons between for-hire firms and those with private fleets indicated that for-hire firms have a considerably higher value of time.

The primary limitation in the analysis of the value of time is the lack of RP data, which led to the use of SP methods. In the absence of economic data derived from observed behavior, researchers are left with taking consumers at their word. While it has previously been shown that SP methods routinely underestimate value of time, most of the underestimate should be accounted for by using many different scenarios and taking the maximum of the presentations as the maximum willingness to pay for each subject.

The truncation of the data provided some limitations in the modeling that could be done to extract the estimate for the value of time. The truncation could account for the data not following the expected log-normal distribution.
The small sample size limited the number of variables that could be used to explain the variance in value of time. The budget and time horizon for the study limited the sample size when interviews were used to conduct the analysis, but it was felt that the quality of the data from interviews overcame this limitation.

Previous SP surveys estimate the value of time using trade-offs that involve fee scenarios, which many respondents in this analysis indicated an aversion to this approach. Considering the maximum of fines versus fees provides a new way of looking at the question. Further research is needed to corroborate SP estimates with existing RP data. Little RP value of time data exist in the field of commercial trucking, but the analysis should be done where both sets of data are obtainable.

Future freight value-of-time analysis using the ASP technique should increase the upper bound to eliminate the truncation problem that was encountered. A reasonable upper limit would be $\$ 160$. This would still possess all the attractive properties that $\$ 80$ had for meaningful integer values when bisected repeatedly. 


\section{APPENDIX}

\section{Interview Questions}

1. How many miles did company trucks travel during 2002? (if they didn't answer in first cut survey)

2. What is you operating cost per mile? Per ton mile?

Labor

Fuel and oil

Maintenance

Parking and tolls

Registration and taxes

Insurance

Vehicle purchase / lease

3. How many axles are on an average company truck?

4. What percentage of trucks are sent out loaded to capacity?

5. What role, if any, does road quality play in route selection?

6. Are there any specific roads drivers try to avoid due to poor road quality?

7. If SLR causes your firm to operate different kinds of trucks than it would under normal conditions, what factors are considered before reaching a decision on truck type?

8. What was your total operating cost for the fiscal / calendar year 2002?

Now we would like you to take a survey that will give us a better idea of how SLR affects trucking decisions as compared to ordinary operation. The survey consists of approximately 30 questions, and each question will present you with two options. There are 5 sets of questions, each with different instructions indicated by a color change. Select the option that would be most preferred by your firm and then click the "next" button. The survey should take about 10 minutes to complete. Please notify me if you have questions at any point during and upon your completion of the survey.

9. If this firm were to purchase a seasonal permit, what would be done differently during SLR? Follow Up.

10. If this firm were to purchase a single use permit, what would be done differently during an otherwise average SLR trip? Follow Up. 
ASP Presentations

\section{Instruction Page}

Thank you for agreeing to participate in this study. Clicking "Continue" will take you to the survey instrument, which consists of approximately 30 questions. The survey is adaptive based on your previous responses. You will be given two options. Please answer each question as your company would make its decisions. There are six sets of questions; each new set is indicated by a color change in the instructions. The survey should take about 10 minutes.

1. Think about your operation. Based on the following choices describing number of truck loadtruckloads and time per truck loadtruckload for a particular shipment, which option would you choose?

2. Think about your operation. If you could pay for a single use permit per truck loadtruckload for each truck loadtruckload to take an otherwise restricted, shorter route during the spring load restriction period that would save each truck loadtruckload one hour, which option would you choose?

3. Think about your operation. If you could pay for a single use permit so that each truck loadtruckload could be loaded to the truck's capacity, resulting in fewer truck loadtruckloads for a particular shipment, which option would you choose?

4. Think about your operation. If you could pay for a seasonal permit so that each truck loadtruckload could be loaded to the truck's capacity, resulting in fewer truck loadtruckloads over the spring load restriction period, which option would you choose?

5. Think about your operation. If you could run overweight and take a restricted, shorter route during the spring load restriction period so that each truck loadtruckload would save one hour, which option would you choose? The expected fine shown is the full fine amount multiplied by your chance of being caught for each truck loadtruckload.

6. Think about your operation. If each truck loadtruckload could be loaded to the truck's capacity, resulting in fewer truck loadtruckloads for a particular shipment, which option would you choose? The expected fine shown is the full fine amount multiplied by your chance of being caught. 


\section{Endnotes}

1. One might ask if the starting point, maximum or minimum biases the results. This was not tested, but would make a good question for future research. It is believed, because firms can assess their value of time better than individual subjects, that so long as the value of their time is within the range, one will obtain reasonable results and the starting point will not produce a significant bias. However, if firms have a value of time above the maximum (in this case \$80), they will choose that maximum, which might skew the analysis, hence the use of the tobit model to account for the cases (eight out of large number) where that occurred.

\section{References}

Adkins, W. G., A. W. Ward, and W. F. McFarland. Values of Time Savings of Commercial Vehicles (NCHRP Report 33). Highway Research Board, Washington D.C., 1967.

Bergkvist, E. "Estimating Value of Time and Forecasting Transport Choice in Road Freight with a Non-Linear Profit Specification: The Logit Model Versus Neural Networks." Umeå Economic Studies No 540. Umeå, Sweden: Umeå University, 2000.

Brownstone, D., A. Ghosh, T. F. Golob, C. Kazimi, and D. Van Amelsfort. 'Drivers' Willingnessto-Pay to Reduce Travel Time: Evidence from the San Diego I-15 Congestion Pricing Project." Transportation Research Part A, 37, (2003): 373-387.

Bruzelius, N. The Value of Travel Time. Croom Helm, London, UK, 1979.

Fowkes, A. S. The Leeds Adaptive Stated Preference. Working Paper 558, University of Leeds, 2001.

Haning, C. R., and McFarland, W. F. Value of Time Saved to Commercial Motor Vehicles Through Use of Improved Highways. (Bulletin No. 23). Texas A \& M University, Texas Transportation Institute, College Station, Texas, 1963.

Lam, T. C. and K. A. Small. "The Value of Time and Reliability: Measurement from a Value Pricing Experiment." Transportation Research Part E; 37, (2001): 231-251.

Louviere, J. J., D. A. Hensher, and J. D. Swait. Stated Choice Methods: Analysis and Application. University Press, Cambridge, UK, 2000.

Kawamura, K. "Commercial Vehicle Value of Time and Perceived Benefit of Congestion Pricing.” Dissertation (Ph.D). University of California at Berkeley, 1999.

Kawamura, K. "Perceived Value of Time for Truck Operators." Transportation Research Record 1725, (2000): 31-36.

Nerhagen, L. Travel Demand and Value ofTime: Towards an Understanding of Individuals Choice Behavior. Kompendiet-Göteborg, Sweden, 2001.

Richardson, A. J. "Simulation Study of Estimation of Individual Specific Values of Time by Using Adaptive Stated-Preference Survey." Transportation Research Record 1804, (2002): 117125. 
Tobin, J. "Estimation of Relationships for Limited Dependent Variables." Econometrica 26,

(1958): 24-36.

U.S. Bureau of Labor Statistics, Division of Consumer Prices and Price Indexes [cited October 16, 2003]. Consumer Price Indexes,-: 2003. Available from World Wide Web: (http://www.bls.gov/cpi/home.htm).

Waters, W.G., C. Wong, and K. Megale. "The Value of Commercial Vehicle Time Savings for the Evaluation of Highway Investments: A Resource Saving Approach." Journal of the Transportation Research Forum 35 (1), (1995): 97-113.

Wynter, L.M. "The Value of Time of Freight Transport in France: Estimation of Continuously Distributed Values from a Stated Preference Survey." International Journal of Transport Economics 22, (1995): 151-165.

\section{Acknowledgements}

The authors would like to acknowledge the Minnesota Department of Transportation and the Minnesota Local Road Research Board for their financial support of the Cost-Benefit Study of Spring Load Restrictions of which this analysis was a part.

Brian Smalkoski received a B.A. degree in geology and management with a minor in economics from the University of Minnesota at Morris. He completed his M.S. degree in civil engineering at the University of Minnesota, Twin Cities, in December of 2003. He is currently working for Kimley-Horn and Associates, Inc. in Tallahassee, Fla., performing consulting engineering services.

Dr. David Levinson is an Assistant Professor in the Department of Civil Engineering at the University of Minnesota. He is the author of three books: Financing Transportation Networks, Assessing the Benefits and Costs of ITS (with David Gillen), and The Transportation Experience (with William Garrison). 